\title{
Raiva no Estado do Rio de Janeiro, Brasil: análise das ações de vigilância e controle no âmbito municipal
}

\author{
Rabies in the State of Rio de Janeiro, Brazil: \\ analysis of surveillance and control actions in the municipal field
}

Flavio Fernando Batista Moutinho ${ }^{1}$

Elmiro Rosendo do Nascimento ${ }^{1}$

Rita Leal Paixão ${ }^{2}$

${ }^{1}$ Departamento de Saúde Coletiva Veterinária e Saúde Pública, Faculdade de Veterinária, Universidade Federal Fluminense (UFF) Rua Vital Brazil Filho 64, Santa Rosa. 24230 340 Niterói RJ Brasil. flaviomoutinho@id.uff.br ${ }^{2}$ Departamento de Fisiologia e Farmacologia, Instituto Biomédico, UFF.

\begin{abstract}
Rabies is an anthropozoonosis characterized by acute viral encephalitis with a lethality rate close to $100 \%$, and it has undergone an epidemiologic transition in which the cycle involving chiroptera is increasing in importance. The scope of this research sought to analyze the rabies surveillance and control actions carried out in municipalities in the State of Rio de Janeiro. Questionnaires were distributed to a representative sample of zoonosis control service managers proportionately calculated in accordance with the Health Regions, according to the State Regionalization Guidance Plan. The data gathered was recorded and analyzed using descriptive statistical techniques. Based on the results attained, the conclusion reached is that the rabies surveillance and control actions were being unsatisfactorily conducted, especially for items related to the monitoring of vampire bat colonies, viral circulation surveillance, notification and monitoring of suspect or aggressive animals, quantification of dog population and population control of stray dogs. The surveillance and control of rabies was being neglected, and was not a priority in the health services in the municipalities evaluated.
\end{abstract}

Key words Rabies, Epidemiology, Surveillance
Resumo A raiva é uma antropozoonose caracterizada por encefalite viral aguda, com letalidade próxima de 100\%, e que vem passando por uma transição epidemiológica na qual o ciclo envolvendo quirópteros vem crescendo em importância. O objetivo da presente pesquisa foi analisar as ações de vigilância e controle da raiva desenvolvidas em municípios do Estado do Rio de Janeiro. Foram aplicados questionários a uma amostra representativa de gestores dos serviços de controle de zoonoses, proporcionalmente calculada em função das Regiões de Saúde, de acordo com o Plano Diretor de Regionalização do Estado. Os dados foram tabulados e trabalhados com técnicas de estatística descritiva. Com base nos resultados encontrados pode-se concluir que as ações de vigilância e controle da raiva estavam sendo desenvolvidas de maneira insatisfatória, principalmente nos itens monitoramento das colônias de morcegos hematófagos, vigilância da circulação viral, notificação e acompanhamento de animais suspeitos ou agressores, quantificação da população canina e controle populacional de cães não domiciliados. A vigilância e o controle da raiva estavam sendo negligenciados e não eram uma prioridade dos serviços de saúde dos municípios avaliados.

Palavras-chave Raiva, Epidemiologia, Vigilância 


\section{Introdução}

A raiva é uma antropozoonose caracterizada por encefalite viral aguda, com letalidade próxima de $100 \%$. Causada por um Lyssavirus, afeta e é transmitida por mamíferos, e se caracteriza por apresentar quatro ciclos epidemiológicos: o aéreo, envolvendo os morcegos; o rural, envolvendo os animais de produção; o urbano, envolvendo cães e gatos e o silvestre terrestre, envolvendo saguis, cachorros do mato e raposas, dentre outros animais ${ }^{1}$.

A raiva canina ainda ocorre de maneira generalizada em mais de 80 países, predominantemente naqueles não desenvolvidos. Metade da população mundial vive em áreas endêmicas de risco para a doença. Em diversos países e continentes a raiva canina já foi eliminada, como na América do Norte, Europa Ocidental, Japão e muitas áreas da América do Sul2.

O ciclo aéreo vem apresentando grande crescimento no País ${ }^{3}$, inclusive no Estado do Rio de Janeiro ${ }^{4}$. O risco de transmissão do vírus pelo morcego é sempre elevado, independentemente de espécie e gravidade do ferimento, logo, toda agressão por morcego é considerada grave ${ }^{1}$. As alterações ambientais que vêm ocorrendo nas áreas rurais vêm interferindo na distribuição espaçotemporal de diversas enfermidades zoonóticas ${ }^{5}$. Além da já citada questão ambiental ${ }^{6}$, a falta de planejamento urbano e projetos arquitetônicos e paisagísticos inadequados contribuem para o grande crescimento populacional de morcegos, hematófagos ou não, em áreas urbanas? .

Dentre os fatores de risco para a ocorrência da raiva destacam-se: baixa cobertura vacinal canina, presença de cães errantes, comunitários ou com acesso livre à rua, existência de casos suspeitos ou confirmados de raiva em cães e gatos ${ }^{1}$, alterações ambientais e ocorrência de casos de raiva em morcegos hematófagos ${ }^{6}$.

De acordo com a Organização Mundial de Saúde, um programa de controle da raiva em animais domésticos deve atuar, em ordem de prioridade, na vigilância epidemiológica, na imunização e no controle da população canina ${ }^{8}$. O Programa Nacional de Controle da Raiva (PNCR), criado em 1973 pelo Ministério da Saúde, tem como principais linhas de ação de controle da doença: a vacinação de cães e gatos, o tratamento profilático de pessoas expostas, a vigilância epidemiológica, o diagnóstico laboratorial, o controle da população animal e a educação em saúde. Importante salientar que a execução das ações do PNCR é atribuição do nível municipal, a partir das metas pactuadas com os níveis estadual e federal ${ }^{3}$.

Dentre as estratégias de prevenção e controle da raiva, destacam-se: monitoramento da circulação viral com encaminhamento de amostras para análise laboratorial, vacinação anual de $80 \%$ da população de cães e gatos ${ }^{1}$, observação clínica de cães e gatos, tratamento das pessoas expostas ao risco, controle de focos da doença e educação em saúde ${ }^{9}$. No caso da raiva rural, o gado deve ser vacinado periodicamente e deve-se trabalhar para a redução da população de morcegos hematófagos. Para tanto, deve-se utilizar a identificação de abrigos e animais atacados, realização de captura e aplicação de anticoagulantes nos morcegos hematófagos, estímulo ao uso de anticoagulantes nas mordeduras em animais de produção e estímulo à inviabilização de abrigos $\operatorname{artificiais}^{10}$.

Avaliação do PNCR revelou diversos problemas no programa, como baixa cobertura vacinal canina, baixo encaminhamento de amostras para diagnóstico em alguns estados, deficiência na integração dos órgãos de saúde pública e agropecuária na maioria dos estados e deficiência na vigilância epidemiológica da raiva silvestre ${ }^{3}$. Um dos grandes problemas em relação à imunização da população de cães e gatos deve-se à questão da determinação do quantitativo populacional existente. No intuito de evitar que parcela destes animais deixem de ser vacinados, deve-se realizar periodicamente o censo canino ou outro método que possibilite o dimensionamento populacional ${ }^{9}$. Estudos vêm demonstrando este problema aliado à consideração de populações como homogêneas em áreas que não o são, como fatores de insucesso para o controle da raiva em áreas urbanas $^{11}$. No contexto do Programa de Controle da Raiva, do Ministério da Saúde, a relação habitante/cão é o parâmetro utilizado para definir a população canina a ser vacinada ${ }^{12}$.

Pesquisas vêm mostrando diferentes proporções entre as populações humanas e de cães e gatos, em diferentes regiões do Brasil ${ }^{11-15}$. Neste contexto, a adoção de uma razão única para toda a América Latina, como preconizado pela Organização Mundial de Saúde, pode trazer erros a essas estimativas das populações de cães ${ }^{12,16}$. Pesquisa em que foi estudado o perfil epidemiológico da raiva no Estado do Rio de Janeiro, no período 1981 a 2007, verificou cobertura vacinal de cães acima de $100 \%$ em diversas regiões do estado em diversos períodos, o que demonstra deficiência na estimativa da população animal existente ${ }^{4}$. 
O objetivo da presente pesquisa foi analisar as ações de vigilância e controle da raiva desenvolvidas em municípios do Estado do Rio de Janeiro.

\section{Material e métodos}

\section{Área de estudo}

O Estado do Rio de Janeiro, com uma área total de $43.766,6 \mathrm{~km}^{2}$, situa-se na Região Sudeste e está dividido em 92 municípios. No que diz respeito ao âmbito do Sistema Único de Saúde (SUS), é utilizada uma divisão geográfica em dez Regiões de Saúde, de acordo com o definido no Plano Diretor de Regionalização do Estado ${ }^{17,18}$.

\section{Amostragem}

A amostra, composta por 47 municípios, foi selecionada a partir da fórmula para estudo de proporções $^{19}$, com nível de significância de 95\%, frequência esperada de $50 \%$ e erro máximo permitido de $10 \%$, considerando o total de municípios do Estado $(\mathrm{N}=92)$. Foi utilizada a Amostragem Estratificada Proporcional ${ }^{20}$, ou seja, as Regiões de Saúde foram consideradas como estratos mais homogêneos quando comparadas ao Estado como um todo e, a partir daí, foi respeitada a proporcionalidade em relação à quantidade de municípios existentes em cada uma delas. Definida a quantidade de municípios a serem pesquisados em cada Região de Saúde (um na Capital, dois na Baía da Ilha Grande, quatro na Metropolitana II e na Norte, cinco na Baixada Litorânea, seis na Noroeste, Centro-Sul, Metropolitana I e na Médio-Paraíba e sete na Serrana), procedeuse à seleção dos mesmos, a qual foi feita por meio de sorteio aleatório simples.

\section{Levantamento de dados}

Definida a amostra, foram feitas visitas aos referidos municípios, nos anos de 2012 e 2013, onde os responsáveis pelos serviços de controle de zoonoses responderam a um questionário estruturado com perguntas fechadas, previamente testado $^{19,21}$, após assinarem o Termo de Consentimento Livre e Esclarecido.

\section{Tabulação e análise estatística dos dados}

Os dados foram codificados, tabulados em planilhas do software Excel $^{\circledast}$ e analisados com técnicas de estatística descritiva, com estudo de frequência e submissão ao teste do quiquadrado para verificação da significância estatística, com comparação entre as regiões.

\section{Consideração ética}

A presente pesquisa foi aprovada pelo Comitê de Ética em Pesquisa da Faculdade de Medicina/ Hospital Universitário Antônio Pedro/UFF.

\section{Resultados e discussão}

\section{Caracterização dos gestores}

Somente 46,8\% $(n=22)$ dos gestores de Serviços de Controle de Zoonoses (SCZ) eram servidores públicos estatutários, sendo que 27,7\% (n =13) do total recebiam gratificação ou comissão para o exercício da função. 40,4\% $(\mathrm{n}=19)$ eram cargos comissionados, caracterizados por serem de livre nomeação pelo gestor municipal, independentemente de serem ou não funcionários concursados do município. Quando se avalia a distribuição por Região de Saúde nota-se que as regiões da Baía da Ilha Grande $(\mathrm{n}=2)$ e da Capital $(\mathrm{n}=1)$ tinham $100 \%$ dos gestores como servidores públicos, comissionados e gratificados ou não. Deve-se atentar para o fato da região da capital ser composta somente por um município. Destaque, ainda, para a região Noroeste, com $67,7 \%(n=4)$ e a Baixada Litorânea, com $60 \%$ $(\mathrm{n}=3)$ de gestores servidores públicos, gratificados e comissionados ou não. Por outro lado, as regiões Centro-Sul $(\mathrm{n}=4)$, Médio Paraíba ( $\mathrm{n}=$ 4) e Metropolitana I $(n=4)$ apresentavam $66,7 \%$ e a região Serrana tinha $57,2 \%(n=4)$ de cargos comissionados ou contratos por tempo determinado. As diferenças entre as regiões são estatisticamente significativas $(\mathrm{p}<0,05)$.

Um dos itens firmados pelos municípios no Pacto de Gestão do SUS, em 2006, foi a adoção de vínculos de trabalhos que garantissem os direitos sociais e previdenciários ${ }^{22}$. Ainda assim, é comum que os empregos no setor saúde sejam preenchidos num contexto de precarização do trabalho, em que muitos dos direitos trabalhistas deixam de ser garantidos, gerando um ambiente de insegurança e ameaça ao trabalhador do SUS ${ }^{23}$. Como nas palavras de Faria e Dalbello -Araújo ${ }^{24}$, os trabalhadores precarizados do SUS encontram-se "imersos em um ambiente de instabilidade e vivenciando cotidianamente sentimentos de impotência, desvalorização, angústia, sofrimento e tensão frente à possibilidade de de- 
missão e suas consequências". O fato do gestor de um SCZ ser um servidor de carreira pública torna-se interessante, pois ele permite, de certa maneira, a continuidade das ações implementadas. Isso se dá porque, dentre as vantagens do regime estatutário, segundo os próprios gestores municipais do SUS, encontra-se a permanência e o vínculo $^{22}$.No que diz respeito à escolaridade dos gestores de SCZ, 95,7\% $(\mathrm{n}=45)$ destes tinham nível superior completo e 4,3\% ( $\mathrm{n}=2)$ nível médio. Dos gestores de nível superior, $48,9 \%$ ( $\mathrm{n}=$ 22) eram pós-graduados em nível de especialização, 8,9\% $(\mathrm{n}=4)$ em nível de mestrado e 2,2\% $(n=1)$ em nível de doutorado. Quando se avalia a distribuição por Região de Saúde encontra-se certa homogeneidade, com as regiões da Capital $(\mathrm{n}=1)$, Baixada Litorânea $(\mathrm{n}=5)$, Centro-Sul ( $\mathrm{n}$ =6), Médio Paraíba $(\mathrm{n}=6)$, Metropolitana II ( $\mathrm{n}$ $=4)$, Noroeste $(\mathrm{n}=6)$, Norte $(\mathrm{n}=4)$ e Serrana ( $\mathrm{n}$ =7) apresentando $100 \%$ de gestores com nível superior completo. As diferenças entre as regiões são estatisticamente significativas $(\mathrm{p}<0,05)$.

Quanto à formação em nível de graduação dos gestores de SCZ verificou-se que $80 \%(n=36)$ eram médicos veterinários, $13,3 \%(\mathrm{n}=6)$ eram biólogos e 6,7 \% $(n=3)$ eram graduados em outra área. Na distribuição por Região de Saúde, observa-se o predomínio dos médicos veterinários em todas as regiões. As diferenças entre as regiões são estatisticamente significativas $(\mathrm{p}<0,05)$.

É importante que os SCZ sejam geridos por médicos veterinários, pois dentre as competências privativas desta profissional encontra-se a assistência técnica e sanitária aos animais. Dentre as competências não privativas encontra-se o exercício de atividades ou funções relacionadas ao estudo e à aplicação de medidas de saúde pública no tocante às zoonoses ${ }^{25}$. Além disso, é de competência privativa do médico-veterinário o exercício das funções de direção, assessoramento e consultoria, em quaisquer níveis da administração pública cujas atribuições envolvam, principalmente, aplicação de conhecimentos inerentes à formação profissional do médico-veterinário ${ }^{26}$. A gerência dos programas de controle de zoonoses e a responsabilidade técnica de SCZ devem ser exercidas por médicos veterinários. Já a coordenação dos programas pode ficar a cargo dos biólogos ${ }^{27}$.

\section{Análise das ações de vigilância e controle da raiva desenvolvidas pelos municípios}

\section{Desenvolvimento de atividades educativas} sobre raiva

Ações educativas sobre raiva eram desenvolvidas em 95,7\% ( $n=45)$ dos municípios. Em 36,2\% $(\mathrm{n}=17)$ eram realizadas somente atendendo à demanda, em 31,9\% ( $\mathrm{n}=15)$ anualmente e em $17 \%(\mathrm{n}=8)$ somente no período de campanha de vacinação. Os municípios que não realizavam nenhuma ação pertenciam às regiões Médio Paraíba e Norte. As diferenças entre as regiões são estatisticamente significativas $(\mathrm{p}<0,05)$.

A OMS considera a educação apropriada a cada realidade um dos sustentáculos que vêm garantindo o sucesso dos programas de controle da raiva em diversos países do mundo ${ }^{2}$. Pesquisa realizada em Recife, $\mathrm{PE}$, mostrou que em relação à posse responsável, 92,2\% dos indivíduos entrevistados associavam cuidados com os animais à vacinação antirrábica e $100 \%$ deles vacinavam seus animais ${ }^{28}$. O manejo inadequado de cães, que pode levar a situações que incrementem a agressividades destes animais ${ }^{29}$, a quantidade de acidentes envolvendo os cães, inclusive com crianças ${ }^{30}$, e a comprovada circulação do vírus da raiva no Brasil, são justificativas para que as atividades educativas envolvendo a raiva sejam desenvolvidas durante todo o ano e reforçadas nas épocas de campanha de vacinação.

\section{Registro de espoliação de cão ou gato por morcego hematófago}

Houve registro de espoliação de cão ou gato por morcego hematófago somente em 19,1\% (n = 9) dos municípios, mas em 6,4\% $(n=3)$ dos municípios não souberam informar sobre esta situação, logo, a quantidade pode ser um pouco maior. Estes registros ocorreram na Capital (n =1), região Médio Paraíba (16,7\% dos municípios/ $\mathrm{n}=1$ ), Metropolitana I ( $50 \%$ dos municípios $/ \mathrm{n}=3)$, Metropolitana II ( $50 \%$ dos municípios $/ \mathrm{n}=2)$, Noroeste $(16,7 \%$ dos municípios $/ \mathrm{n}$ =1) e Serrana $(14,3 \%$ dos municípios $/ \mathrm{n}=1)$. As diferenças entre as regiões são estatisticamente significativas $(\mathrm{p}<0,05)$.

A ocorrência de raiva transmitida por morcegos vem crescendo consideravelmente no Brasil. Há diversos estudos em diferentes regiões apontando este crescimento, além da mudança de perfil epidemiológico da doença ${ }^{31-33}$, principalmente na zona rural ${ }^{33}$. No Estado do Rio de Janeiro esta mudança de perfil epidemiológico já foi identificada em diversas regiões ${ }^{4}$. Tal fato torna-se mais 
preocupante por causa do crescimento que vem sendo observado nas populações morcegos nas áreas urbanas ${ }^{34-36}$.

\section{Registro de espoliação de humanos por morcego hematófago}

Espoliações de humanos por morcegos hematófagos foram registradas somente em 14,9\% $(\mathrm{n}=7)$ dos municípios, mas $12,8 \%(\mathrm{n}=6)$ não souberam precisar esta informação, logo, o número de registros positivos pode ser maior. Tais registros ocorreram nas regiões da Baixada Litorânea em 20\% (n=1) dos municípios, Médio Paraíba em 33,3\% (n=2), Metropolitana I em $16,7 \%(n=1)$, Metropolitana II em 25\% ( $n=2)$, Norte em 25\% ( $\mathrm{n}=1)$ e Serrana em 14,3\% ( $\mathrm{n}=$ $1)$. As diferenças entre as regiões são estatisticamente significativas $(\mathrm{p}<0,05)$.

Os humanos são considerados fontes secundárias de alimentação para os morcegos hematófagos, só sendo espoliados quando há escassez de animais. O risco maior ocorre para os indivíduos de baixa renda e que vivem em moradias precárias $^{37}$. A quantidade de registros de espoliação de humanos por morcegos encontrada na presente pesquisa pode ser considerada baixa, o que está de acordo com diversas pesquisas, nas quais este tipo de espoliação costuma ter baixa prevalência quando comparada com aquelas envolvendo outras espécies ${ }^{38-40}$.

\section{Realização de monitoramento}

\section{de colônias de morcegos hematófagos}

Somente $8,5 \%(\mathrm{n}=4)$ dos municípios realizavam monitoramento de colônias de morcegos hematófagos, sendo um município na Capital, um na região Metropolitana II, um na Noroeste e um na Serrana. As diferenças entre as regiões são estatisticamente significativas $(\mathrm{p}<0,05)$.

O cadastro e monitoramento de colônias de morcegos é uma atribuição, a princípio, do governo do Estado, através dos órgãos de Defesa Sanitária ${ }^{6}$. Dada a dimensão do Estado e as limitações da Defesa Sanitária fluminense, é de bom alvitre que o município também desenvolva tal ação, apesar das dificuldades de recursos que possam existir, principalmente nas cidades de médio e grande portes ${ }^{41}$. Em pesquisa realizada no Estado do Rio de Janeiro por Oliveira et al. ${ }^{4}$ foi sugerido o incremento da ação de monitoramento das colônias de morcegos como forma de melhorar os resultados do Programa de Controle da Raiva e enfrentar a mudança do perfil epidemiológico da doença, com o crescimento da incidência em quirópteros.

\section{Realização de censo da população canina}

Dos 47 municípios, somente 17\% $(\mathrm{n}=8)$ realizaram censo da população de cães no período avaliado. Na região da Baía da Ilha Grande, 100\% $(\mathrm{n}=2)$ dos municípios informaram ter realizado, enquanto no Médio Paraíba foram 50\% $(\mathrm{n}=2)$, na Centro-Sul e na Metropolitana I 16,7\% ( $\mathrm{n}=$ 1) e na Serrana $14 \%(n=1)$. Nas demais regiões não foi realizado censo no período. As diferenças entre as regiões são estatisticamente significativas $(\mathrm{p}<0,05)$

No Estado do Rio de Janeiro é comum os municípios apresentarem coberturas vacinais acima de $100 \%$ da população animal estimada ${ }^{4}$, reflexo do desconhecimento do real tamanho das populações de cães e gatos. Quando a análise de séries históricas de cobertura vacinal mostram resultados constantemente acima de $80 \%$, pode ser um indicativo de subestimativa da real população canina, sendo necessária a correção das metas. $\mathrm{O}$ censo ou outro método de dimensionamento da população canina, é que vai evitar a ocorrência de erros de estimativa populacional e, consequentemente, de cobertura vacinal ${ }^{42,43}$. Oliveira et al. ${ }^{44}$ também detectaram a carência de um censo que possibilitasse dados confiáveis sobre a população canina, em pesquisa realizada na Paraíba.

\section{Atingimento da meta}

de vacinação antirrábica

A meta de vacinação de cães contra raiva foi alcançada por $77 \%(\mathrm{n}=36)$ dos municípios nos três anos do período avaliado. A meta foi alcançada em somente dois anos em 4\% $(\mathrm{n}=2)$ dos municípios e em somente um ano em $6 \%$ ( $n=$ $3)$ dos municípios. Treze por cento $(n=6)$ dos municípios não alcançaram a meta em nenhum dos três anos. As regiões da Capital $(\mathrm{n}=1)$, Baixada Litorânea $(n=5)$, Médio Paraíba $(n=6)$ e Noroeste $(n=6)$ cumpriram $100 \%$ da meta nos três anos. Não cumpriram a meta em nenhum dos três anos 50\% dos municípios da Baía da Ilha Grande $(\mathrm{n}=1)$ e da região Metropolitana I ( $\mathrm{n}=$ 3), 16,7\% ( $n=1)$ da Centro-Sul e 14\% $(n=1)$ da Serrana. As diferenças entre as regiões são estatisticamente significativas $(\mathrm{p}<0,05)$.

A vacinação antirrábica gratuita em massa é o elemento mais eficaz para o controle e a erradicação da raiva urbana. Somente na América Latina cerca de 45 milhões de cães vêem sendo vacinados anualmente, levando a declínios significativos da enfermidade na região ${ }^{2}$. No Estado do Rio de Janeiro a campanha começou a ser realizada em 1983 e alcançou grande sucesso, com 100\% dos municípios a realizando anualmente desde o iní- 
cio da década de 1990. Desde 2001 não é diagnosticado um caso da doença em cão ou gato no Esta$\mathrm{do}^{4}$. O resultado encontrado na presente pesquisa, com o predomínio de alcance da meta ministerial, é comum no Brasil ${ }^{40,45,46}$. Apesar disso, deve-se atentar para o fato dos dados de cobertura vacinal nem sempre serem fidedignos tendo em vista a dificuldade de se conhecer o real tamanho da população de animais domésticos em cada município. Sendo assim, a ocorrência de subvacinação não pode ser descartada. Não se pode esquecer, também, que existe uma parcela da população que leva seus animais para serem vacinados exclusivamente em estabelecimentos privados e estes números não são computados nas campanhas de vacinação. Pesquisa realizada em Campo Grande, MS, mostrou que $16,7 \%$ dos proprietários vacinavam seus animais nestes locais ${ }^{11}$.

\section{Encaminhamento ao laboratório}

\section{de amostra de material biológico de cão}

O encaminhamento de amostra de material biológico de cães ao laboratório para verificação da circulação viral do vírus da raiva foi realizado somente por $8,5 \%(\mathrm{n}=4)$ dos municípios nos três anos do período estudado. Além disso, 17\% $(\mathrm{n}=8)$ dos municípios encaminharam em pelo menos um dos anos do período avaliado, mas $4,3 \%(\mathrm{n}=2)$ não souberam precisar esta informação, logo, esta quantidade pode ser um pouco maior. Os municípios da Baixada Litorânea $(\mathrm{n}=$ 6), Metropolitana II $(\mathrm{n}=4)$ e Centro-Sul $(\mathrm{n}=6)$ não fizeram o encaminhamento em nenhum dos anos do período avaliado. Somente 50\% $(\mathrm{n}=1)$ dos municípios da Baía da Ilha Grande, 25\% ( $\mathrm{n}$ = 1) da Norte e $16,7 \%(n=1)$ das regiões Metropolitana I e Noroeste conseguiram fazer o encaminhamento nos três anos do período avaliado. As diferenças entre as regiões são estatisticamente significativas $(\mathrm{p}<0,05)$.

O pactuado entre os municípios e o Ministério da Saúde é que seja encaminhado para diagnóstico laboratorial material biológico de 0,2\% da população canina, anualmente. Apesar disso, há indicação de que $0,1 \%$ já seja suficiente ${ }^{47}$. A raiva animal é considerada endêmica no Estado do Rio de Janeiro, havendo comprovadamente circulação do vírus em herbívoros e outros mamíferos ${ }^{4}$. A vigilância dessa circulação viral é muito importante para o controle da doença ${ }^{1}$, mas para que tal ação seja satisfatória e dê os resultados almejados há necessidade de laboratórios de referência bem localizados, bem estruturados e em quantidade suficiente. A dificuldade de encaminhar estas amostras é uma realidade no
Brasi $^{48,49}$. Acredita-se que a estrutura laboratorial do Estado do Rio de Janeiro seja insuficiente para o processamento da quantidade prevista e mal distribuída do ponto de vista espacial, dificultando o encaminhamento das amostras pelos municípios. De acordo com a OMS é altamente recomendável que a capacidade laboratorial permita a vigilância eficaz da raiva ${ }^{2}$.

\section{Encaminhamento ao laboratório de} amostra de material biológico de morcego

No período avaliado, $77 \%(\mathrm{n}=36)$ dos municípios não encaminharam amostra de material biológico de morcego para diagnóstico de raiva em nenhum dos anos. O encaminhamento ocorreu nos três anos do período somente na Capital $(100 \% / \mathrm{n}=1)$. Nas regiões Médio Paraíba, Metropolitana I e Metropolitana II, ocorreu em $16,7 \%(\mathrm{n}=1)$. Nas regiões da Baía da Ilha Grande, Baixada Litorânea, Centro-Sul e Norte não houve encaminhamento em nenhum dos anos. As diferenças entre as regiões são estatisticamente significativas $(\mathrm{p}<0,05)$.

Conforme discussão anterior, o perfil epidemiológico da raiva no Brasil vem passando por um processo de alteração em que há um crescimento da importância dos quirópteros como fonte de infecção em detrimento dos cães. Até 2009, 41 espécies de morcegos já haviam sido identificadas no Brasil com o vírus da raiva ${ }^{35}$. Muitos morcegos, hematófagos ou não, vêm sendo encontrados infectados, inclusive no Rio de Janeiro $^{50-52}$. O ciclo aéreo da raiva torna possível a circulação do vírus nas áreas urbanas. Neste contexto, o diagnóstico para a confirmação da circulação viral em quirópteros oportuniza o desenvolvimento de medidas de prevenção e controle $^{53}$, principalmente quando se considera que os morcegos não hematófagos também vêm sendo encontrados infectados e têm um contato mais próximo com humanos e animais domésticos, expondo-os ao risco ${ }^{54}$.

\section{Notificação ao SINAN dos casos de agressão de animais a humanos \\ (atendimento antirrábico)}

A notificação ao Sistema Nacional de Agravos de Notificação (SINAN) das agressões

de cães a humanos era realizada em todos os casos somente por $57 \%(\mathrm{n}=27)$ dos municípios, com destaque para os da região da Baía da Ilha Grande, onde $100 \%(\mathrm{n}=2)$ sempre notificavam e Centro-Sul e Médio Paraíba, onde 83,3\% ( $\mathrm{n}=5)$ sempre notificavam. Importante notar que $14,9 \%$ $(\mathrm{n}=7)$ não souberam informar se esta notifica- 
ção era realizada e $6,4 \%(n=3)$ não notificavam nenhum caso. Destes, 67,7\% $(n=2)$ estavam localizados na região Noroeste e 33,3\% $(n=1)$ na região Serrana. As diferenças entre as regiões são estatisticamente significativas $(\mathrm{p}<0,05)$.

Estes resultados são semelhantes aos encontrados em levantamento feito no Estado do Rio de Janeiro, que mostrou que $60 \%$ dos municípios não faziam a notificação dos atendimentos antirrábicos ${ }^{4}$. Em Minas Gerais, Oliveira et al. ${ }^{40}$ também encontraram quantidade considerável de municípios silenciosos para o atendimento antirrábico humano.

A notificação no Brasil é considerada compulsória, de acordo com a Portaria no 104/2011 do Ministério da Saúde ${ }^{55}$. Como visto, havia uma grande quantidade de municípios que não realizava integralmente as notificações e uma considerável quantidade de municípios em que o gestor do SCZ não soube informar se a notificação era ou não realizada, demonstrando falta de integração entre seu setor e o setor de Vigilância Epidemiológica. De acordo com a OMS os dados epidemiológicos devem ser recolhidos, processados, analisados e divulgados de maneira rápida entre os setores para permitir uma adequada vigilância da raiva ${ }^{2}$. No início dos anos 2000 já havia uma sinalização das dificuldades com os sistemas de informação envolvendo a raiva no Brasil $^{3}$. Os dados epidemiológicos são fundamentais tanto para a profilaxia pós-exposição de humanos quanto para os veterinários adotarem as medidas de controle e bloqueio de foco ${ }^{1}$. A ausência de comunicação adequada entre os profissionais envolvidos na vigilância e no controle da raiva podem levar a falhas nestas atividades ${ }^{40}$.

\section{Acompanhamento de cães mordedores e suspeitos de raiva}

Somente 49\% ( $n=23)$ dos municípios faziam acompanhamento de todos os casos de cães mordedores e suspeitos de raiva pelo período recomendado pelo Ministério da Saúde. Destaque para a Capital $(100 \% / \mathrm{n}=1)$ e regiões Norte $(75 \% / \mathrm{n}=3)$ e Centro-Sul $(66,7 \% / \mathrm{n}=4)$. Nenhum dos casos era acompanhado em 21\% ( $\mathrm{n}=$ 10) dos municípios, com destaque para a região da Baía da Ilha Grande, onde 50\% $(\mathrm{n}=1)$ dos municípios não faziam acompanhamento. As diferenças entre as regiões são estatisticamente significativas $(\mathrm{p}<0,05)$.

$O$ cão que tenha agredido algum humano deve ser observado por dez dias, independentemente de encontrar-se sadio ou não no momento da agressão ${ }^{1}$. Dentre as agressões a humanos re- alizadas por outras espécies de animais, a maior ocorrência encontrada envolve os cães, atingindo até $90 \%$ dos $\operatorname{casos}^{38-40,56}$. Estudos alertam para o fato da ficha do SINAN para atendimento antirrábico não conter informação sobre a procedência do animal agressor, a qual é fundamental para que se possa rastreá-lo e acompanhá-lo ${ }^{18,40,56}$. Este fato pode estar atrapalhando ou inviabilizando o acompanhamento dos cães pela municipalidade, apesar da existência de um campo para "observações" onde tais dados poderiam ser anotados caso fosse implementado um protocolo para tal. Além disso, a inexistência de canis de observação e de recursos humanos e materiais suficientes para o acompanhamento domiciliar são considerados pontos críticos. É comum a inexistência de instalações apropriadas para o acompanhamento dos animais, principalmente nos municípios de menor porte, como foi identificado por Gomes et al. ${ }^{57}$ no Estado de São Paulo, onde mais de $68 \%$ dos municípios não contavam com as mesmas.

\section{Ações de controle populacional de cães desenvolvidas nos municípios}

Apesar de 44,7\% ( $\mathrm{n}=21)$ dos gestores de SCZs considerarem a densidade populacional de cães não domiciliados existentes em seus municípios como grande, proporção que chega a $87,3 \%$ $(\mathrm{n}=41)$ se somados aos gestores que a qualificaram como mediana, somente $46,8 \%(n=22)$ dos municípios desenvolviam algum tipo de ação em relação ao controle populacional. Dentre estas atividades eram realizadas ações educativas, esterilização gratuita ou subsidiada, projeto de adoção, recolhimento e manutenção em canil, dentre outras. O fato da maior parte dos municípios $(53,2 \% / n=25)$ não realizarem nenhuma ação é preocupante já que se trata de uma importante atividade de prevenção e controle da raiva ${ }^{1}$.

A superpopulação de cães não domiciliados é reconhecida ${ }^{57,58}$, variando de região para região em função da condição social ${ }^{59,60}$, da disponibilidade de abrigo e alimentos no ambiente ${ }^{9,61}$ e do tamanho do município ${ }^{13}$. Mas cães muitas vezes considerados pela população como não domiciliados, em função da falta de coleira ou identificação, são, na verdade, semi-domiciliados ${ }^{62-64}$. Estudo de dimensionamento da população de cães no interior de São Paulo encontrou 32\% de cães semidomiciliados ${ }^{13}$. Em pesquisa realizada em Botucatu, SP, 53,7\% dos entrevistados afirmaram que seus cães tinham acesso à rua, sendo que $69,4 \%$ sozinhos $^{65}$. Em Curitiba, PR, até 2005, quase $90 \%$ dos cães recolhidos das ruas eram semidomiciliados ${ }^{66}$. 
O grande percentual de municípios que não desenvolvem atividades de controle populacional de cães não domiciliados pode ser justificado: pelo descaso ${ }^{67}$; pela heterogeneidade social, política, econômica e cultural que acarreta respostas diferenciadas de acordo com cada realidade ${ }^{57}$; pela falta de informação sobre o assunto ${ }^{68}$; e pela falta de uma política nacional para o setor ${ }^{69}$.

\section{Conclusão}

As ações de vigilância e controle de fatores de risco para a raiva estavam sendo desenvolvidas de maneira insatisfatória no Estado do Rio de Janeiro, principalmente nos itens monitoramento das colônias de morcegos hematófagos, vigilância da circulação do vírus da raiva, notificação e acompanhamento de animais suspeitos ou agressores, quantificação da população de cães do município e controle populacional de cães não domiciliados. A vigilância e o controle da raiva estavam sendo negligenciados e não eram uma prioridade dos serviços de saúde dos municípios avaliados.

\section{Colaboradores}

FFB Moutinho, ER Nascimento e RL Paixão participaram igualmente de todas as etapas de elaboração do artigo.

\section{Referências}

1. Brasil. Ministério da Saúde (MS). Guia de vigilância epidemiológica. Brasília: MS; 2009.

2. World health organization (WHO). WHO expert consultation on rabies - 2005. [acessado 2013 nov 19]. Disponível em: http://www.who.int/rabies/trs931_\%2006 _05.pdf

3. Organização Panamericana de Saúde, Brasil. Ministério da Saúde. Avaliação do Programa Nacional de Controle da Raiva no Brasil. [acessado 2011 ago 4]. Disponível em http://www.paho.org/cdmedia/hdmvp01/ docs.rabia/paises/EVAL.RABIA.BRASIL.pdf

4. Oliveira ASS, Bezerra FFM, Azevedo FRMA. Descrição do perfil epidemiológico da raiva no Estado do Rio de Janeiro no período de 1981 a 2007. Rev Rede de Cuidados em Saúde 2010; 4(2):1-12.

5. Peres F. Saúde, trabalho e ambiente no meio rural brasileiro. Cien Saude Colet 2009; 14(6):1995-2004.

6. Brasil. Ministério da Agricultura. Controle da raiva dos herbívoros: manual técnico. Brasília: MAPA; 2009.

7. Kotait I, Aguiar EAC, Carrieri ML, Harmani NMS. Manejo de quirópteros em áreas urbanas. São Paulo: Instituto Pasteur; 2003.

8. Organização Mundial da Saúde (OMS). O controle da raiva: oitavo relatório do comitê de especialistas da OMS em raiva. Goiânia: Ed. UFG; 1999.

9. Reichmann MLB, Figueiredo ACC, Pinto HBF, Nunes VFP. Controle de populações de animais de estimação. São Paulo: Instituto Pasteur; 2000. № 6.

10. Kotait I, Gonçalves CA, Peres NF, Souza MCAM, Targueta MG. Controle da Raiva dos Herbívoros. São Paulo: Instituto Pasteur; 1998.

11. Domingos IH, Rigo L, Honer MR. Perfil da populações canina e felina no município de Campo Grande, MS. Ensaios e Ciência: Ciências Biológicas, Agrárias e da Saúde 2007; 11(1):97-103.
12. Rocha MDG, Silva LBG, Brandespin DF, Tenório TGS, Nunes ERC. Dimensionamento da população canina domiciliada e avaliação da cobertura vacinal anti-rábica nos municípios da V Gerência Regional de Saúde, Estado de Pernambuco. Vet. e Zootec. 2011; 18(3):474480.

13. Alves MCGP, Matos MR, Reichmann ML, Dominguez MH. Dimensionamento da população de cães e gatos do interior do Estado de São Paulo. Rev Saude Publica 2005; 39(6):891-897.

14. Andrade AM, Queiroz LH, Perri SHV, Nunes CM. Estudo descritivo da estrutura populacional canina da área urbana de Araçatuba, São Paulo, Brasil, no período de 1994 a 2004. Cad Saude Publica 2008; 24(4):927-932.

15. Mascarenhas NMF, Hilst CLS, Souza MSB, Martins MIM, Pirolo J, Nabut LB, Machado MA, Navarro IT, Frühvald E, Zanoni FP, Tokiyoshi AF, Lacerda LCC. Posse responsável e controle populacional de cães e gatos e sua contribuição para a redução da eutanásia na população errante de Londrina e região. Anais do $35^{\circ}$ Congresso Brasileiro de Medicina Veterinária. [acessado 2009 nov 13]. Disponível em: http://www.sovergs.com. br/conbravet2008/anais/cd/resumos/R0706-1.pdf

16. Dias RA, Garcia RC, Silva DF, Amaku M, Ferreira Neto JS, Ferreira F. Estimativa de populações canina e felina domiciliadas em zona urbana do Estado de São Paulo. Rev Saude Publica 2004; 38(4):565-570.

17. Rio de Janeiro. Secretaria de Estado de Saúde. Plano Diretor de Regionalização. Rio de Janeiro: Secretaria de Estado de Saúde; 2001.

18. Comissão Intergestores Bipartite. Deliberação $n^{\circ}$ 753/2009. Constituição do Comitê Gestor Regional da Capital. [acessado 2011 ago 5]. Disponível em www. cib.rj.gov.br/deliberacoes-cib 
19. Thrusfield M. Epidemiologia veterinária. $2^{\mathrm{a}}$ ed. São Paulo: Roca; 2004.

20. Barbetta PA Estatística aplicada às Ciências Sociais. $8^{\mathrm{a}}$ ed. Florianópolis: UFSC; 2012.

21. Hill MM, Hill A. Investigação por questionário. 2a ed. Lisboa: Ś́labo; 2005.

22. Junqueira V, Cortizo CT, Vieira NP, Santos APL, Santos FS, Lacaz FAC. O Pacto pela Saúde e a gestão da força de trabalho na Atenção Básica do SUS: um retrato da situação de alguns municípios no Estado de São Paulo. Physis 2011; 21(2):675-693.

23. Souza MASL. As Novas Configurações do Trabalho em Saúde: os indicativos do processo de desregulamentação. Textos \& Contextos 2010; 9(2):334-344.

24. Faria HX, Dalbello-Araújo M. Precarização do trabalho e processo produtivo do cuidado. Mediações 2011; 16(1):142-156.

25. Brasil. Lei no 5517, de 23 de outubro de 1968. Dispõe sôbre o exercício da profissão de médico veterinário e cria os Conselhos Federal e Regionais de Medicina Veterinária. Diário Oficial da União 1968; 25 out.

26. Brasil. Decreto no 64.704, de 17 de junho de 1969. Aprova o Regulamento do exercício da profissão de médico-veterinário e dos Conselhos de Medicina Veterinária. Diário Oficial da União 1969; 24 jun.

27. Reichmann MAB, Sandoval MRC, Formaggia DME, Pressoto D, Nunes VFP, Santos LS, Glasser CM, Costa MAF. Orientação para projetos de Centros de Controle de Zoonoses (CCZ). 2a ed. São Paulo: Instituto Pasteur; 2000.

28. Lima AMA, Alves LC, Faustino MAG, Lira NMS. Percepção sobre o conhecimento e profilaxia das zoonoses e posse responsável em pais de alunos do pré-escolar de escolas situadas na comunidade localizada no bairro de Dois Irmãos na cidade do Recife (PE). Cien Saude Colet 2010; 15(1):1457-1464.

29. Santana JA, Almeida LP. Ocorrência de agressões por cães: caracterização da situação de domicílio do animal agressor e espaço geográfico de agressão. Anais do IX Encontro Interno e XIII Seminário de Iniciação Científca. Uberlândia: UFU, 2009. [acessado 2014 jan 11]. Disponível em: https://ssl4799.websiteseguro.com/swge5/ seg/cd2009/PDF/IC2009-0100.pdf

30. Del Ciampo LA, Ricco RG, Almeida CAN, Bonilha LRCM, Santos TCC. Acidentes de mordeduras de cães na infância. Rev Saude Publica 2000; 34(4):411-412.

31. Santos MFC, Resende RM, Sobrinho RNS, Vieira S. Diagnóstico laboratorial da raiva no Estado de Goiás no período de 1976 a 2001. Ciência Animal Brasileira 2006; 7(1):77-83.

32. Queiroz LH, Carvalho C, Buso DS, Ferrari CIL, Pedro W. Perfil epidemiológico da raiva na região Noroeste do Estado de São Paulo no período de 1993 a 2007. Rev. Soc. Bras. Med. Trop 2009; 42(1):9-14.

33. Wada MY, Rocha SM, Maia-Elkhoury ANS. Situação da raiva no Brasil, 2000 a 2009. Epidemiol. Serv. Saúde 2011; 20(4):509-518.

34. Deus GT, Becer M, Navarro IT. Diagnóstico da raiva em morcegos não hematófagos na cidade de Campo Grande, Mato Grosso do Sul, Centro Oeste do Brasil: descrição de casos. Semina: ciências agrárias 2003; 24(1):171-176.

35. Sodré MM, Gama AR, Almeida MF. Updated list of bat species positive for rabies in brazil. Rev.Inst. Med. Trop. 2010; 52(2):75-81.
36. Moutinho FFB, Rocha MRD, Borges FVB, Pereira AG. Reclamações da comunidade à Seção de Controle de População Animal do Centro de Controle de Zoonoses de Niterói, Rj, Brasil, no período 2006-2010. R. bras. Ci. Vet. 2013; 20(1):26-31.

37. Rio de Janeiro. Secretaria de Estado de Saúde. Manual para manejo de morcegos e controle da raiva. Sem data. [acessado 2010 fev 12]. Disponível em: http://pt.scribd. com/doc/38130728/Manual-de-Morcego-Atualizado

38. Franzo VS, Scherma MR, Oliveira, RC, Andriani SF, Coladeti Júnior OA, Piasentin AN, Traldi AL, Miranda VF. Prevalência de ataques anual através da mordedura de animais com potencialidade de transmissão da raiva no município de Leme, Estado de São Paulo, 20042006. Rev Ciências Veterinárias 2007; 5(5):91-95.

39. Buso DS, Nunes CM, Queiroz LH. Características relatadas sobre animais agressores submetidos ao diagnóstico de raiva, São Paulo, Brasil, 1993-2007. Cad Saude Publica 2009; 25(12):2742-2751.

40. Oliveira VMR, Pereira PLL, Silva JA, Miranda CFJ, Rodrigues KO, Rodrigues TO, Moreira EC. Mordedura canina e atendimento antirrábico humano em Minas Gerais. Arq. Bras. Med. Vet. Zootec. 2012; 64(4):891-898.

41. Fabian MH. A experiência do Rio Grande do Sul. In: Kotait I, Harmani NMS, Carrieri ML, Aguiar EAC. Manejo de quirópteros em áreas urbanas. São Paulo: Instituto Pasteur; 2003. p. 20-24.

42. Reichmann MLB, Bonadia MLA, Ferreira HB, Nunes VFP. Vacinação contra a raiva de cães e gatos. São Paulo: Instituto Pasteur; 1999.

43. Matos MR, Alves MCGP, Reichmann MLAB, Dominguez MHS. Técnica Pasteur São Paulo para dimensionamento de população canina. Cad Saude Publica 2002; 18(5):1423-1428.

44. Oliveira AVB, Silva RA, Gomes AAB. A campanha nacional de vacinação contra raiva animal nos municípios da microrregião de Catolé do Rocha - PB, no período de 2006 a 2007. Revista Verde 2010; 5(1):101-119.

45. Pavoulid-Corrêa A, Serra-Freire NM. Inquérito sobre cobertura vacinal antirrábica de cães e gatos na área metropolitana do Rio de Janeiro-RJ. Rev. Cien. Agrár. 2009; 52:131-136.

46. Silva MHS, Silva JA, Magalhães DF, Silva MX, Meneses JNC, Moreira EC. Caracterização demográfica e epidemiológica de cães e gatos domiciliados em Barbacena, MG. Arquivo Brasileiro de Medicina Veterinária e Zootecnia 2010; 62(4):1002-1006.

47. Schneider MC, Almeida GA, Souza, LM, Moraes NB, Diaz RC. Controle da raiva no Brasil de 1980 a 1990 Rev Saude Publica 1996; 30(2):196-203.

48. Passos ADC, Silva AAMCC, Ferreira AHC, Silva JM, Monteiro ME, Santiago RC. Epizootia de raiva na área urbana de Ribeirão Preto, SP, Brasil. Cad Saude Publica 1998; 14(4):735-740.

49. Miranda CFJ, Silva JA, Moreira EC. Raiva humana transmitida por cães: áreas de risco em Minas Gerais, Brasil, 1991-1999. Cad Saude Publica 2003; 19(1):9199.

50. Silva MV, Xavier SM, Moreira WC, Santos BCP, Esbérard CEL. Vírus rábico em morcego Nyctinomops laticaudatus na Cidade do Rio de Janeiro, RJ: isolamento, titulação e epidemiologia. Rev. Soc. Bras. Med. Trop. 2007; 40(4):479-481. 
51. Carneiro NFF, Caldeira AA, Antunes AA, Carneiro VF, Carneiro GF. Raiva em morcegos Artibeus lituratus em Montes Claros, Estado de Minas Gerais. Rev. Soc. Bras. Med. Trop. 2009; 42(4):449-451.

52. Albas A, Souza EAN, Picolo MR, Favoretto SR, Gama $\mathrm{AR}$, Sodré MM. Os morcegos e a raiva na região oeste do Estado de São Paulo. Rev. Soc. Bras. Med. Trop. 2011; 44(2):201-205.

53. Babboni SD, Modolo JR. Raiva: Origem, Importância e Aspectos Históricos. UNOPAR Cient Ciênc Biol Saúde 2011; 13(Esp):349-356

54. Albas A, Souza EAN, Lourenço RA, Favoretto SR. Perfil antigênico do vírus da raiva isolado de diferentes espécies de morcegos não hematófagos da Região de Presidente Prudente, Estado de São Paulo. Rev. Soc. Bras. Med. Trop. 2009; 42(1):15-17.

55. Brasil. Ministério da Saúde. Portaria no 104, de 25 de janeiro de 2011. Define as terminologias adotadas em legislação nacional, conforme o disposto no Regulamento Sanitário Internacional 2005 (RSI 2005), a relação de doenças, agravos e eventos em saúde pública de notificação compulsória em todo o território nacional e estabelece fluxo, critérios, responsabilidades e atribuições aos profissionais e serviços de saúde. Diário Oficial da União 2011; 26 jan.

56. Fortes FS, Wouk AFPF, Biondo AW, Barros CC. Acidentes por mordedura de cães e gatos no município de Pinhais, Brasil, de 2002 a 2005. Archives of veterinary science 2007; 12(2):16-24

57. Gomes LH, Menezes RF, Aranda CMSS, Vieira PA. Serviços municipais de controle de zoonoses no Estado de São Paulo: diagnóstico situacional. Bepa 2011; 8(96):11-31.

58. Santana LR, Macgregor E, Almeida e Souza MF, Oliveira TP. Posse responsável e dignidade dos animais. 2004. [acessado 2014 jan 23]. Disponível em: http:// www2.saude.ba.gov.br/divep/arquivos/RAIVA\%20 COVEDI\%202012/VIGIL\%C3\%82NCIA\%20EPIDEMIOL\%C3\%93GICA\%20DA\%20RAIVA\%202012/ Publica\%C3\%A7\%C3\%B5es\%20sobre\%20a\%20Raiva/posse\%20responsavel.pdf. Acesso em 23 de janeiro de 2014

59. Ávila-Pires FD. Zoonoses: hospedeiros e reservatórios. Cad Saude Publica 1989; 5(1):82-97.

60. Shimozako HJ, Amaku M, Dias RA, Ferreira F, Montenegro Netto H, Paranhos, NT. Uso de sistemas de informação geográfica como ferramentas de auxílio na análise de casos de apreensão de animais no município de São Paulo. Rev. Ciênc. Ext 2006; 2(2):1-16.

61. Magnabosco C. População domiciliada de cães e gatos no Município de São Paulo: perfil obtido através de um inquérito multicêntrico [dissertação]. São Paulo: USP; 2006.
62. Frutuoso JCS, Silva LS, Moreira FG, Oliveira RF. Estudo do manejo nutricional, profilático e comportamental na população de cães de São Luis de Montes Belos GO. IV Seminário de Iniciação Científica - UEG, 2006. [acessado 2013 nov 24]. Disponível em: http://www. prp.ueg.br/06v1/conteudo/pesquisa/iniccien/eventos/ sic2006/arquivos/agrarias/estudo_nutricional.pdf

63. Canatto BD, Silva EA, Bernardi F, Mendes MCNC, Paranhos NT, Dias RA. Caracterização demográfica das populações de cães e gatos supervisionados do município de São Paulo. Arquivo Brasileiro de Medicina Veterinária e Zootecnia 2012; 64(6):1515-1523.

64. Dias RA, Mori ACF, Canatto BD, Silva EA, Bernardi F, Mendes MCNC, Paranhos NT. Os donos do pedaço: caracterização das populações de cães e gatos domiciliados no município de São Paulo. São Paulo: Faculdade de Medicina Veterinária e Zootecnia; 2013. 127 p.

65. Langoni H, Troncarelli MZ, Rodrigues EC, Nunes HRC, Harumi V, Henriques MV, Silva KM, Shimono JY. Conhecimento da população de Botucatu - SP sobre Guarda Responsável de cães e gatos. Vet e Zootec 2011; 18(2):297-305.

66. Biondo AW, Cunha GR, Silva MAG, Fuji KY. Carrocinha não resolve. Revista do Conselho Regional de Medicina Veterinária - PR, 2007; 5(25):20-21.

67. Santana L, Marques MR. Maus tratos e crueldade contra animais nos Centros de Controle de Zoonoses: aspectos jurídicos e legitimidade ativa do Ministério Público para propor Ação Civil Pública. 1998. [acessado 2009 out 14]. Disponível em: http://www.forumnacional.com.br /maus_tratos_CCz_de_Salvador.pdf

68. Garcia RC. Controle de populações de cães e gatos em área urbana: uma experiência inovadora na Grande São Paulo. Saúde Coletiva 2005; 2(5):24-28.

69. Garcia RC, Calderón N, Ferreira F. Consolidação de diretrizes internacionais de manejo de populações caninas em áreas urbanas e proposta de indicadores para seu gerenciamento. Rev. Panam. Salud Publica 2012; 32(2):140-144.

Artigo apresentado em 24/03/2014

Aprovado em 05/08/2014

Versão final apresentada em 07/08/2014 